\title{
A Probe into the Development Laws of Large Gas Fields
}

\author{
Yuping SUN ${ }^{1,2, a^{*}}$, Jialiang $L U^{2, b}$, Hongjun TANG ${ }^{2, c}$ \\ ${ }^{1}$ University of Chinese Academy of Science, Beijing, China; ${ }^{2}$ Research Institute of Petroleum \\ Exploration and Development, Langfang, Hebei, China \\ a sunyuping01@petrochina.com.cn, ${ }^{b} j$ llu69@petrochina.com.cn, ${ }^{c}$ tanghj69@petrochina.com.cn
}

Keywords: large gas fields; development law; stable production period; EUR; peak shaving; resource security strategy

Abstract. Large gas fields occupy a dominant position in natural gas exploration and development. Many of them are at their mature stage and most are exploited effectively. Therefore it is necessary to study their successful experience to guide undeveloped gas fields. Based on analysis of more than 200 mature large gas fields, the general laws are discussed. Firstly, large gas fields should guarantee a long stable production period through two different kinds of styles. Secondly, EUR of large gas fields is generally high if successful measures are implemented against development risks mainly including uncertainties of structural features, reservoir permeability and drive mechanism. Thirdly, large gas fields need to undertake more responsibility to deal with short-term peak shaving based on strict criteria of suitable characteristics. Finally, more protection priority should be given to strategic gas fields while taking long-term resource security strategy into account.

\section{Introduction}

The exploration and development of gas fields worldwide has had a history of more than 170 years. Much experience in the operation of certain kinds of gas fields has been accumulated, such as the development laws of carbonate reservoirs, fractured reservoirs and deep-water reservoirs. Yet studies concerning the summarization of operation expertise and management skills of general large gas fields are few. As large gas fields occupy absolutely important position in the natural gas industry, it is of vital significance to probe into the successful operation and management expertise of such large gas fields. Such study might prove valuable for those undeveloped gas fields.

\section{Large Gas Fields Distribution}

This research is based on C\&C Reservoir and IHS database. Statistics show that there are 355 large gas fields around the world by the end of 2007, accounting for $2 \%$ of the total number. But their reserve is approximately 183 TCM, accounting for $73 \%$ of the whole world. That means large gas fields play a vital role much as their number is small ${ }^{[1,2,3]}$.

The distribution of large gas fields is not balanced from the global perspective. They are concentrated in a few countries. Statistics shows that the top 17 countries account for $60 \%$ of the number and $88 \%$ reserves of the world's gas fields Meanwhile, statistics also show that 242 large gas fields are at their mature stage. Those fields will be analyzed carefully to shed some light on the expertise of their successful operation. 


\section{Development Laws of Large Gas Fields}

\section{Longer stable production period in different styles}

Large gas fields usually play an important role in meeting the market demand. They need to maintain stable production to keep downstream market more smooth and steady. Stable production period is the key parameter to reflect the ability to maintain this stable supply. In this study, stable production period of 62 large mature gas fields is analyzed, and results show that large gas fields usually have a longer stable production period, generally 7-25 years, 13 years by average (Fig.1). So, 10 years at least is proposed for longer stable supply of large gas fields

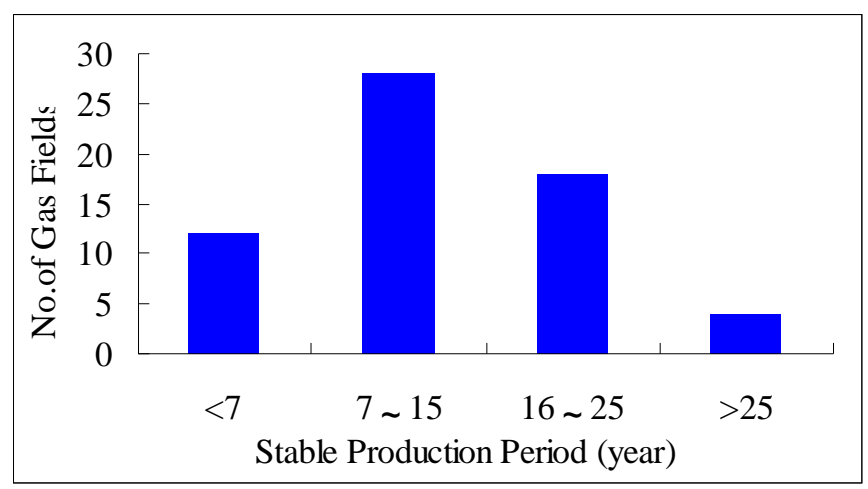

Fig.1 Distribution of stable production period of 62 large mature gas fields

But different fields present different ways to maintain stable production. Their styles can be classified into two types. One is to achieve long-term stable production through long period production of single well. Lacq ${ }^{[4]}$ in France is a good example (Fig.2). This kind of fields should have high reservoir permeability, excellent formation connectivity, low water driving force and high single well production.
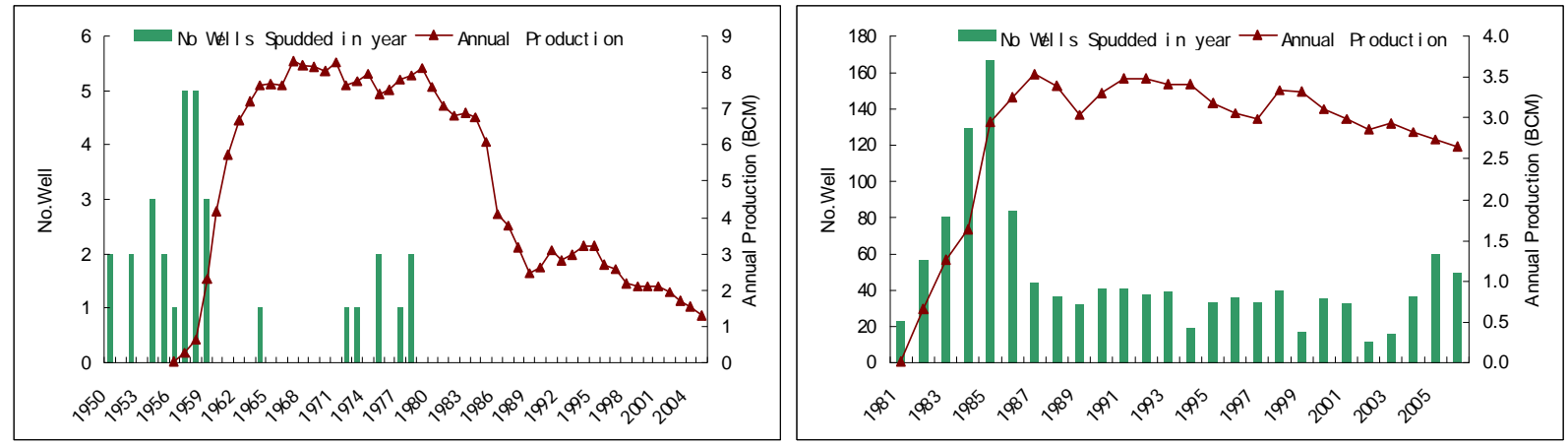

Fig.2 Annual production and No. of new wells of Lacq (Left) and KuparukRiver (Right)

The other way is to drill many new wells year by year instead of drilling all wells simultaneously, such as the KuparukRiver ${ }^{[5]}$ in USA (Fig.2). Such kind of fields always represents the following characteristics: low reservoir permeability, discontinuous reservoir, poor single well productivity, complex geological features and high risk of exploitation. This style of operation is suitable for unconventional gas resources, including tight sandstone reservoir, coal bed methane and shale gas. Gas production of a single well in unconventional gas resource is usually very low. This is conducive to tapping a huge number of wells. The method above can reduce initial capital expenditure and diversify investment in time axis in favor of decreasing exploitation risk. 


\section{Higher EUR through effective risk-avoiding measures}

In general, large gas fields have a higher estimated ultimate recovery (EUR) compared with middle and small ones (Fig.3). Factors, both objective and subjective, result in this phenomenon simultaneously. On the one hand, large gas fields have so abundant reserves that they have longer time to exploit. During that long term, effective management experience and technology will be accumulated in the early stage and used to exploit the rest of the reserves with a high EUR in return. On the other hand, huge reserves need huge investment which results in low cost. Low cost results in low abandoned boundary. Thus, EUR will be enhanced while abandoned boundary declines.

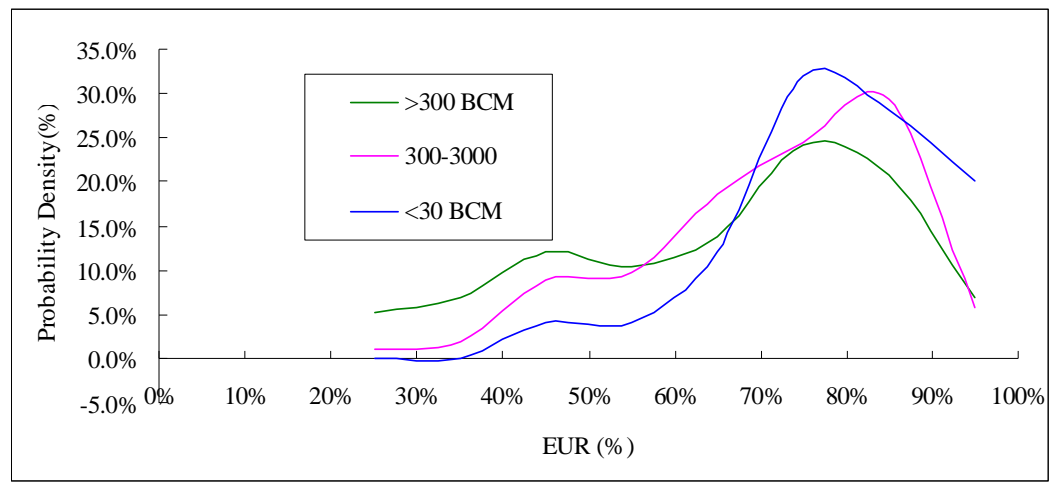

Fig.3 Probability distribution of EUR in 182 large gas fields

However, there are still few exceptions. Those failures usually occurred in reservoir with very big geological uncertainty, such as Beaver River with a 12\% EUR. In the early stage, many key parameters, such as bottom water activity and fracture development degree are uncertain. But those uncertainties are ignored. In fact, the bottom water is very active and the fracture is developed which leads to severe water influx and sharp decline of gas production. As a result, EUR becomes very low. Owing to some subjective conditions, it is impossible to make sure what the geological features are, especially in the early developing stage. So it is necessary to strengthen risk assessment and lay out pertinent measures against potential risks to ensure efficient development. The earlier the measures are laid out, the better the effect is.

The weight of different parameters controlling the EUR is evaluated. The result shows that the most important objective parameters are drive mechanism, structural feature, N/G ratio, and reservoir permeability.

\section{Function of short-term peak shaving}

One of the extraordinary features of gas industry is its seasonal fluctuation of gas consumption, represented by an enormous ratio between downstream demand and upstream supply. That means production needs to expand in winter when market demand is great, while in summer it needs to reduce when market demand is low. One effective method is to use reserved production capacity from existing gas fields. The European gas market is a classic example. The regional peak amplitude, ratio between average higher consuming month and lower one, is $135 \%$ in 2010 . The main suppliers including Holland and Britain frequently use conserved production capacity located in North Sea Basin to resolve the fluctuation ${ }^{[6]}$.

Gas fields suitable for peak shaving usually possess the following features: large reserve and production scale, good physical characteristics, close to the consuming market, especially for regions of obvious contradiction of supply-and-demand, perfect ground transfer system, lack of UGR. 


\section{Protection priority in resource security}

Strategic gas fields usually refer to those fields which have the power to control a region's or a country's supply market. Because of their huge reserve and production capacity, they are usually kept within their full capacity as a precaution against emergency, such as importing interruption, major development accident. Groningen gas field ${ }^{[7]}$, located in the Holland, is a typical case. Its recoverable reserve is more than $2.8 \mathrm{TCM}$ and its peak production exceeded 81.3BCM per year in 1975, accounting for nearly $90 \%$ production of the whole country. However, this field is the only huge gas field. So, after that, the government adopted a strategic adjustment by limiting its production gradually year by year and prioritizing exploiting small ones around the huge fields, which effectively helps to obtain a long-term stable supply of natural gas. Hence, Holland has had a stable market for more than 50 years.

Many countries adopt similar strategies (Table 1). The most important factor for selecting a strategic gas field is the proportion of production. After analyzing several topical strategic gas fields, we recommend that the lowest boundary line is $10 \%$.

Table 1 Some other typical strategic fields

\begin{tabular}{cccc}
\hline Gas field & Country & Development index & Production scale \\
\hline Lacq & France & The country`s largest field , recovery ratio is & Over $36 \%$ of total consumption, \\
nearly $100 \%$ in early stage
\end{tabular}

\section{Summary}

In order to exploit large gas fields effectively, many issues should be considered: long-term stable supply and short-term peak shaving, technical success (high EUR) as well as strategic consideration. Through extensive analysis, the following conclusions have been obtained.

Stable production period of large field is at least 10 years in order to ensure a long-term stable supply. But different fields should adopt different ways to maintain stable production. Unconventional gas resources should avoid drilling all wells simultaneously.

More attention should be paid to development risks. Three kinds of uncertainties include structure features, reservoir permeability and drive mechanism. Only in this way can we obtain a higher EUR.

Large gas fields need to undertake more responsibility to cope with short-term peak shaving. When taking into account long-term resource security strategy, more priority should be given to protection of strategic gas fields, i.e. gas supply over $10 \%$ in the region. 


\section{References}

[1] Halbouty M T. Giant oil and gas fields of the decade 1990-1999, AAPG, Memoir78.Tulsa: AA PG, 2003:1-340.

[2] C\&C, Database of Worldwide oil and gas fields (2008)

[3] IHS, Database of Worldwide oil and gas fields (2007)

[4] C\&C, Exploration and development of Lacq field, inner report (2005)

[5] C\&C, Exploration and development of KuparukRiver field, inner report. (2006)

[6] CIEP, The European market for seasonal storage. Clingendael International Energy Programme (CIEP) discussion paper, February 2006.

[7] C\&C, Exploration and development of Groningen field, inner report.. (2005) 